\title{
CIÊNCIA, TECNOLOGIA E SUAS RELAÇÕES SOCIAIS: A PERCEPÇÃO DE GERADORES DE TECNOLOGIA E SUAS IMPLICAÇÕES NA EDUCAÇÃO TECNOLÓGICA
}

\author{
Science, technology and their social relations: \\ the perception of technology generators \\ and their implications in technological education
}

\author{
Rosemari Monteiro Castilho Foggiatto Silveira ${ }^{1}$ \\ Walter $\mathrm{Bazzo}^{2}$
}

\begin{abstract}
Resumo: O presente artigo tem como objetivo expor a concepção que as pessoas envolvidas (empreendedores e gestores) com o processo de desenvolvimento de inovações tecnológicas dentro de IEBTs (Incubadoras de Empresas de Base Tecnológica) do Paraná possuem sobre ciência, tecnologia, inovação e suas relações com o contexto social. A abordagem metodológica foi a pesquisa qualitativa de natureza interpretativa. A técnica de coleta de dados foi a entrevista individual semiestruturada. A amostra contou com 29 participantes. Os resultados mostraram que a grande maioria dos participantes da pesquisa possui uma visão ainda incipiente sobre ciência, tecnologia e suas relações sociais. Ficou evidenciada a necessidade de se mudar o paradigma atual da educação tecnológica, a fim de transformar a concepção do profissional da área tecnológica quanto a sua responsabilidade social nesse processo.
\end{abstract}

Palavras-chave: CTS. Alfabetização científica e tecnológica. Educação tecnológica. Incubadoras de empresa de base tecnológica. Tecnologia.

Abstract: The main purpose of this paper is to expose the conception of involved people (entrepreneur and managers) have about science, technology, innovation and their relations in the social context, with the development process of technological innovations inside the Incubators of Companies of Technological Base (IEBT) of Paraná. The methodological approach used was interpretative qualitative research. The data collection was individual semi-structuralized interviews. The sample had 29 participants. The results showed that the great majority of the participants of the research still have an unformed vision about science, technology and their relations. The research also showed that it is necessary to change the current paradigm of technology education in order to transform the conception of the professional in the technological area in relation to his/her social responsibility in this process.

Keywords: CTS. Technological and scientific literacy. Technological education. Incubators of companies of technological base. Technology.

${ }^{1}$ Graduada em Farmácia e Bioquímica, Doutora em Educação Científica e Tecnológica; Docente, Departamento de Pós-graduação, Mestrado Profissional em Ensino de Ciência e Tecnologia, Universidade Tecnológica Federal do Paraná. Ponta Grossa, PR, Brasil. foggiattorm@hotmail.com

${ }^{2}$ Engenheiro mecânico, Doutor em Educação; Docente, Departamento de Engenharia Mecânica, Universidade Federal de Santa Catarina. Florianópolis, SC, Brasil. wbazzo@emc.ufsc.br

${ }^{1}$ Av. Anita Garibaldi, 1771, casa 12

Vila Órfãs - Ponta Grossa, PR

84.015-050 
Silveira, R. M. C. F.; Bazzo, W.

\section{Introdução}

A tecnologia tem se apresentado como o principal fator de progresso e de desenvolvimento. No paradigma econômico vigente, ela é assumida como um bem social e, juntamente com a ciência, é o meio para a agregação de valores aos mais diversos produtos, tornando-se a chave para a competitividade estratégica e para o desenvolvimento social e econômico de uma região.

Para manter a competitividade tecnológica e econômica, as empresas estão se estruturando melhor, e políticas governamentais estão sendo desenvolvidas para dar suporte aos processos de inovações tecnológicas. Além disso, universidades públicas e privadas estão criando mecanismos para possibilitar as relações entre academia e indústria, visando garantir o desenvolvimento tecnológico futuro. Dentre os diversos meios para estimular o desenvolvimento de inovações tecnológicas existentes no Brasil, destacamos as Incubadoras de Empresas de Base Tecnológica (IEBTs), as quais vêm sendo criadas com a finalidade de acompanhar as transformações tecnológicas, buscando atender às novas exigências do processo de trabalho e vencer o desemprego. Esse tipo de incubadora tem o propósito de proporcionar às pessoas empreendedoras, interessadas em criar a sua própria empresa de base tecnológica, a oportunidade de participarem de programas de formação na área de criação de negócios.

Temos percebido que muito se tem falado sobre inovação tecnológica na mídia, nos meios acadêmicos, empresariais e nas IEBTs. Incentivos estão sendo criados destinados ao desenvolvimento de inovações tecnológicas. Entretanto, parece que pouco se tem feito para levar reflexões sobre questões que envolvem ciência, tecnologia e inovações com o contexto social, tanto para os meios acadêmicos (universidades, faculdades etc.) como para as IEBTs.

Nesse contexto, na qualidade de professores que vêm trabalhando com a educação tecnológica e que vivenciam todo esse processo de transformação, questionamos: será que as pessoas envolvidas com o processo de geração de inovações tecnológicas dentro das incubadoras de empresas de base tecnológica (IEBT) têm se preocupado com as questões sociais do desenvolvimento científico e tecnológico?

Assim, o presente artigo tem como objetivo apresentar a concepção dessas pessoas em relação à ciência, tecnologia e suas relações com o contexto social. Esclarecemos que os dados apresentados são resultados parciais da tese de doutorado que está sendo desenvolvida no PPGECT (Programa de Pós-Graduação em Educação Científica e Tecnológica) da UFSC (Universidade Federal de Santa Catarina), cujo tema é: "Inovação tecnológica na visão dos gestores e empreendedores de IEBTs do Paraná: desafios e perspectivas para a educação tecnológica”.

\section{Tecnologia: algumas reflexões}

Análoga à história da ciência na modernidade, a tecnologia ${ }^{3}$ sofre e causa transforma-

\footnotetext{
${ }^{3}$ Bazzo, Von Linsingen e Pereira (2003) esclarecem que, diferentemente da técnica que faria referência a habilidades, procedimentos, artefatos desenvolvidos sem a ajuda do conhecimento científico, o termo "tecnologia” seria utilizado para se referir aos sistemas desenvolvidos levando em conta o conhecimento científico.
} 
ções profundas de caráter político, econômico, social e filosófico, na história do séc. XVII em diante. Por isso, Miranda (2002) afirma que a tecnologia moderna não pode ser considerada um mero estudo da técnica. Ela representa mais que isso, pois nasceu quando a ciência, a partir do renascimento, aliou-se à técnica, com o fim de promover a junção entre o saber e o fazer (teoria e prática). Segundo a autora:

A tecnologia é fruto da aliança entre ciência e técnica, a qual produziu a razão instrumental, como no dizer da Teoria Crítica da Escola de Frankfurt. Esta aliança proporcionou o agir-racional-com-respeito-a-fins, conforme assinala Habermas, a serviço do poder político e econômico da sociedade baseada no modo de produção capitalista (séc. XVIII) que tem como mola propulsora o lucro, advindo da produção e da expropriação da natureza. Então, se antes a razão tinha caráter contemplativo, com o advento da modernidade, ela passou a ser instrumental. É nesse contexto que deve ser pensada a tecnologia moderna; ela não pode ser analisada fora do modo de produção, conforme observou Marx. (MIRANDA, 2002, p. 51, grifo da autora)

Nesse sentido, Bastos (1998) corrobora ao afirmar que a tecnologia é um modo de produção, o qual utiliza todos os instrumentos, invenções e artifícios e que, por isso, é também uma maneira de organizar e perpetuar as vinculações sociais no campo das forças produtivas. Dessa forma, a tecnologia é tempo, é espaço, custo e venda, pois não é apenas fabricada no recinto dos laboratórios e usinas, mas recriada pela maneira como for aplicada e metodologicamente organizada.

Isso evidencia que, se considerarmos que a tecnologia moderna está inserida e se produziu num contexto social, político e econômico determinado, então a nossa visão sobre a tecnologia e o seu papel na sociedade deverá ser diferente daquela que prega que a tecnologia é um "mal necessário", pois, se compreendemos que ela surgiu em certo período histórico, ela não é inerente à condição humana, ou seja, não é tão antiga quanto a técnica.

Por isso, é necessário fazermos uma avaliação crítica sobre a tecnologia, sua constituição histórica e sua função social, no sentido de não só compreender o sentido da tecnologia, mas também de repensar e redimensionar o papel da mesma na sociedade. Segundo Miranda (2002), conforme a avaliação dos frankfurtianos, é necessário dirigir a razão (o pensar) para a emancipação do homem, e não para sua escravidão, como ocorre na razão instrumental, e também conduzir a razão para emancipação, com uma maior autonomia da ciência, que nos tempos modernos tornou-se escrava da tecnologia, para redefinir qual a função social da ciência, da técnica e da tecnologia.

Passados mais de três séculos, a história do desenvolvimento tecnológico nos dá condições suficientes para avaliar as significações da tecnologia moderna que modelou a sociedade como industrial, pós-industrial e, por último, da sociedade informática. Miranda (2002) cita que, segundo alguns pensadores da atualidade, como Robert Kurz, Ramonet, Boaventura Santos, vivemos, hoje, o "colapso da modernização", começando pela própria confiança absoluta na ciência que emanciparia o homem de toda escravidão, obscurantismos e medo. Fato que não ocorreu. O que constatamos, na atualidade, é a escravidão do próprio homem pelas suas 
invenções e descobertas tecnológicas, só possíveis graças à aliança entre ciência e técnica. Os autores citados ainda acrescentam que na história da humanidade, nunca tantas pessoas morreram de fome, na miséria ou pela violência, afirmação cujos dados são apontados por Boaventura Santos (2000). Miranda (2002) expõe também a opinião de Hobsbawn (1995) sobre a história do século XX, quando considera que vivemos a era dos extremos, devido aos paradoxos que se nos apresentam. A começar pelo próprio avanço tecnológico de um lado e o extermínio de culturas e povos (seja pela miséria, seja pela guerra) de outro.

Arocena (2004) complementa que a tecnologia tem multiplicado e transformado qualitativamente o poder de produzir e destruir, de curar e depredar, de ampliar a cultura dos seres humanos e de gerar riscos para a vida, sendo que esse poder, associado aos perigos, está distribuído social e regionalmente de maneira muito desigual. Dessa maneira, a ciência e a tecnologia têm feito que o poder se fixe nas mãos de alguns seres humanos.

Pinto (2005, p. 706) reforça essa ideia ao afirmar que:

O conhecimento científico acabaria por absorver em si o destino da humanidade, coisa que muito alegra os filósofos domésticos dos grupos dominantes, porque acreditam significar essa 'fase superior' o comando total e definitivo da humanidade trabalhadora pela minoria de privilegiados.

Vivemos num mundo em que a tecnologia representa o modo de vida da sociedade, na qual a cibernética, automação, engenharia genética, computação eletrônica são alguns dos ícones da sociedade tecnológica que nos envolve diariamente. Por isso, a necessidade de refletir sobre a natureza da tecnologia, sua necessidade e função social.

Para Bazzo, Von Linsingen e Pereira (2003), a imagem convencional da tecnologia é que ela sempre teria como resultado produtos industriais de natureza material, manifestada nos artefatos tecnológicos (máquinas), cuja elaboração tenha seguido regras fixas ligadas às leis das ciências físico-químicas; ou seja, a tecnologia, numa visão convencional, seria a ciência aplicada. Isso implica dizer que a tecnologia é redutível à ciência e que é respaldada pela postura filosófica do positivismo lógico de importante tradição acadêmica, para o qual as teorias científicas são valorativamente neutras, ou seja, os cientistas não são responsáveis pela aplicação da ciência (tecnologia), mas sim a responsabilidade deveria recair sobre aqueles que fazem uso da tecnologia (ciência aplicada). Essa imagem contribuiu para sustentar a ideia de que se a ciência é neutra, os produtos de sua aplicação também são.

Dizer que a tecnologia é uma ciência aplicada, para López e Cerezo (2004), sugere que a aplicação é posterior à aquisição de um conhecimento confiável sobre seus possíveis efeitos, ou seja, a aplicação tecnológica se produz debaixo do amparo do conhecimento teórico. Assim, há poucas possibilidades de se produzirem surpresas desagradáveis, já que o conhecimento científico prévio é a melhor ferramenta para controlar as consequências de uma aplicação tecnológica, pois não se trata de um processo cego de ensaio e erro, e, sim, de uma intervenção no mundo, baseado no conhecimento teórico e do método experimental próprio da ciência moderna. 
Ciência, tecnologia e suas relações sociais ...

\section{Consequências do desenvolvimento científico e tecnológico}

O mundo parece depender cada vez mais do conhecimento científico e tecnológico. A concepção clássica das relações entre ciência, tecnologia e sociedade, muitas vezes presente nos diversos âmbitos do mundo acadêmico e nos meios de divulgação, é uma concepção essencialista e triunfalista, na qual se presume que mais ciência produz mais tecnologia que gera mais riqueza e, consequentemente, mais bem-estar social. Autores como Echeverría (1995), Garcia, Cerezo e López (1996) e López e Cerezo (1996) complementam que ciência e tecnologia são apresentadas como formas autônomas da cultura, como atividades valorativamente neutras, como uma aliança heroica de conquista da natureza.

Cerezo (2002) argumenta que a expressão política dessa autonomia, cuja gestão de mudança científico-tecnológica deve ser deixada nas mãos dos próprios especialistas, teve início depois da Segunda Guerra Mundial, época em que havia intenso otimismo sobre as possibilidades da ciência/tecnologia e apoio incondicional à sua expansão. A elaboração doutrinária desse manifesto de autonomia em relação à sociedade deve sua origem a Vannevar Bush, um cientista norte-americano envolvido no Projeto Manbattan para a construção da primeira bomba atômica. Nesse mesmo período, o cientista também entrega ao então presidente Truman o relatório Science - The Endless Frontier ("Ciência: a fronteira infinita"). Nesse relatório, são definidas as linhas mestras da futura política científico-tecnológica norte-americana, destacando o modelo linear de desenvolvimento, ou seja, que o bem-estar nacional depende do financiamento da ciência básica e o desenvolvimento sem interferências da tecnologia, defendendo que, para que o modelo funcione, é necessário manter a autonomia da ciência.

Dessa forma, o desenvolvimento tecnológico e o progresso social viriam naturalmente. Sobre essa questão, Garcia, Cerezo e López (1996) argumentam que a ciência, somente enquanto a busca da verdade, era concebida como alavanca de desenvolvimento tecnológico, um desenvolvimento que se supunha na base da Revolução Industrial e, em última instância, da realização social dos ideais da revolução política franco-americana. Autores críticos como Marcuse, Habermas ou Feyerabend afirmam que a razão do estado é a razão científica, de forma que o que impera é a tradição instrumental da ciência com sua linguagem de feitos inegáveis e razões inapeláveis. Criticam, ainda, que a democracia era concebida dentro dos limites marcados pela ignorância da população sobre a maioria dos temas importantes; uma ignorância supostamente compensada pela destreza esotérica dos especialistas a serviço do estado e suas corporações.

Apesar de toda euforia em torno do desenvolvimento científico-tecnológico, autores como Garcia, Cerezo e López (1996) e Sanmartín et al. (1992) afirmam que, em meados da década de 1950, indícios apontavam que o modelo linear unidirecional não era tão promissor quanto parecia ser, pois a Rússia, em 1957, colocava em órbita, ao redor da Terra, o Sputnik, um pequeno satélite do tamanho de uma bola, mantendo-se na vanguarda da ciência e da tecnologia, confirmando os indícios de que o modelo linear de desenvolvimento científicotecnológico ocidental estava falhando. Essas desconfianças foram confirmar-se nas décadas seguintes quando ocorrem desastres vinculados ao desenvolvimento científico-tecnológico: vazamentos de resíduos poluentes, acidentes nucleares em reatores civis e de transportes militares, envenenamentos por produtos farmacêuticos, derramamentos de petróleo etc., que serviram para confirmar a necessidade de se revisar a política científico-tecnológica. 
O projeto Manbattan e sua aplicação em Hiroshima, além de outros casos de desenvolvimentos tecnológicos vinculados à guerra e utilização militar, na opinião de Garcia, Cerezo e López (1996), representaram o primeiro ponto de inflexão da concepção otimista do caráter benfeitor da ciência-tecnologia, junto com as preocupações dos problemas ambientais. Publicações como Silent Spring, de Rachael Carson (1962), que levantavam os riscos associados aos inseticidas DDT, e Estrutura das Revoluções Cientificas, de Thomas Kuhn (1962), que introduzia conceitos sociais para explicar a dinâmica e o desenvolvimento da ciência, exerceram influências na reação acadêmica, começando-se a falar sobre os efeitos negativos das tecnologias, assim como se colocava em questão sua neutralidade política, social e econômica que, até o momento, eram tidas como benfeitoras.

Para que o desenvolvimento científico e tecnológico seja menos excludente, é necessário que se levem em conta os reais problemas da população, os riscos técnico-produtivos e a mudança social. Por isso, faz-se necessário ter uma visão interativa e contextualizada das relações entre ciência, tecnologia, inovação e sociedade e, muito especialmente, das políticas públicas mais adequadas para se gestionarem as oportunidades e perigos que envolvem uma mudança técnica. Ou seja, a questão não é tanto se a ciência é boa ou não, mas sim se pode melhorar e como.

A construção de tais políticas pode ser favorecida por meio do movimento CTS (Ciência, Tecnologia e Sociedade) que, nos anos 1960 e 1970, começou a se manifestar na comunidade acadêmica, cuja insatisfação com as concepções tradicionais da ciência e da tecnologia e a preocupação com os problemas políticos e econômicos decorrentes do desenvolvimento científico-tecnológico e com os movimentos sociais de protestos, começou a buscar análise e estudo na área de CTS (Ciência, Tecnologia e Sociedade). No Brasil, tais estudos são muito recentes e, segundo Bazzo (1998, p. 218), essa abordagem posiciona "uma reação social crítica ao cientificismo e à tecnocracia" e busca compreender a dimensão social da ciência e da tecnologia em relação aos fatores de natureza social, política e econômica, responsáveis pela mudança científica e tecnológica, e, também, no que diz respeito às repercussões éticas, ambientais ou culturais dessa mudança.

\section{Estratégia metodológica}

A pesquisa teve uma abordagem qualitativa de natureza interpretativa. Nesse tipo de abordagem, ocorre a busca da interpretação em lugar da mensuração, valoriza-se a indução e assume-se que fatos e valores estão intimamente relacionados, tornando-se inaceitável uma postura neutra do pesquisador. Em seu acontecer natural, defende uma visão holística dos fenômenos, levando em conta todos os componentes de uma situação em suas interações e influências recíprocas (ANDRÉ, 1995, p. 17).

Para a coleta de dados, utilizamos a técnica de entrevista individual semiestruturada. As entrevistas duraram em média sessenta minutos, foram gravadas e transcritas literalmente. 
Ciência, tecnologia e suas relações sociais ...

A amostra foi selecionada intencionalmente, sendo escolhidos gestores das IEBTs e empreendedores com empresas incubadas ${ }^{4}$ e graduadas ${ }^{5}$ em IEBTs do Paraná, totalizando vinte e nove participantes, os quais possuem graduação nas seguintes áreas: artes gráficas, arquitetura e urbanismo, ciências econômicas, designer, desenho industrial, engenharia de computação, engenharia eletrônica, engenharia elétrica, física, engenharia mecânica, química ambiental, tecnologia em eletrotécnica, tecnologia em informática e tecnologia em química.

Para não identificarmos os participantes da pesquisa e, consequentemente, garantirmos o anonimato dos mesmos, utilizamos nomes fictícios.

A análise dos dados foi feita após a leitura de todas as entrevistas de forma indutiva, cuja preocupação foi a de perceber como os participantes encaram as questões abordadas. Os dados foram agrupados e separados por unidades de significados, primeiro numa perspectiva global - levando-se em conta as convergências das informações -, depois, numa perspectiva diferenciada, destacando-se os dados divergentes, que foram apresentados de maneira descritiva. Desse processo de análise emergiram os resultados que serão apresentados na sequência.

\section{A interpretação dos dados}

\section{O contexto científico e tecnológico e sua relação com a sociedade: a percepção dos participantes da pesquisa}

Foi possível observar que a maioria dos entrevistados apresentou certo desconforto quando indagados sobre a relação do contexto científico e tecnológico com a sociedade, pois, muitas vezes, foi preciso repetir a pergunta de maneiras diferentes para que os entrevistados pudessem tecer seus comentários, evidenciando que a questão social do desenvolvimento científico e tecnológico nem sempre é pensada ou está presente nas decisões dos empreendedores.

A maioria $(87 \%)$ dos participantes da pesquisa enxerga o contexto científico e tecnológico como uma alavanca para o desenvolvimento econômico e para a estruturação da sociedade, como pode ser observado, por exemplo, na fala de Og:

"Eu acho que a tecnologia move muito a sociedade, ela é responsável por isso. Ela move porque ela faz girar a economia, porque para você prodų̧ir tecnologia você precisa gerar o capital intelectual e precisa de pessoas que estudem, porque a tecnologia não pode ser feita por pessoas sem estudo, o qual gera o conbecimento. Uma tecnologia nova gera novas tecnologias em cima daquelas que estão sendo desenvolvidas. Então, ela vai girando todos os ciclos da sociedade, da economia, do emprego."

\footnotetext{
${ }^{4}$ São empresas que estão instaladas dentro das incubadoras. Estas empresas podem permanecer por, no máximo, três anos dentro da incubadora.

${ }^{5}$ Empresas graduadas são as empresas que já saíram da incubadora. As empresas podem se graduar antes de dois anos.
} 
Os entrevistados também expressaram que o desenvolvimento científico-tecnológico só é atrativo se tiver retorno comercial. Alegam que, na universidade, é possível fazer pesquisas, experiências sem visar o lado econômico, mas na empresa, isso só interessa se for lucrativo, se compensar economicamente, o que pode ser observado na argumentação de Nelson:

\begin{abstract}
"Eu trabalho na Universidade como professor e pesquisador e tenho experiência como empreendedor. Acho que na Universidade, como funcionário efetivo, tenho oportunidade de pesquisar e fazer experiências, experimentar. O nosso compromisso é com a busca de soluções. Na empresa nós não temos esta oportunidade, porque toda atividade desenvolvida pela empresa tem que ser paga pela empresa. A empresa pode dizer "vamos fazer uma nova pesquisa sobre um novo produto". Essa pesquisa, que estiver sendo feita, vai consumir horas de trabalho profissional e a empresa vai ter que pagar. Como que a empresa vai pagar alguma coisa? Ela paga com o dinheiro das vendas dos seus produtos. Para se fazer pesquisa numa empresa ela precisa ter produtos que estão sendo vendidos, que gerem receita além do necessário para cobrir os seus custos para cobrir as atividades de pesquisas. Se as atividades de pesquisa não gerarem alguma solução, algum produto comercializado, ela é um fator de despesa para a empresa, é um fator negativo para a empresa. Nas empresas tem que ser muito mais pragmático em termos de pesquisa em ciência, em inovação. Tudo isso interessa, sim, desde que possa ter um retorno comercial. É a vida da empresa que está em jogo. Os múltiplos resultados sociais da empresa, se não conseguir manter estrutura de caixa, tudo isso não vai existir, vai desaparecer porque ela não vai se manter."
\end{abstract}

Nessa perspectiva, o desenvolvimento científico e tecnológico só interessa para as empresas se for para gerar lucro, ou seja, a prioridade é econômica. Tal fato parece ser uma constante entre os empreendedores. Jonash e Sommerlatte (2001, p.145), citam uma pesquisa realizada nos Estados Unidos, na qual se constatou que, embora os analistas financeiros achem que os novos produtos e a criatividade sejam significativos para a inovação, os fatores que prevalecem como indicadores são o lucro e os ganhos dos acionistas. Reforçando essa postura, Marcovitch (2003, p. 355) afirma: "as inovações geram maiores ganâncias que as meras especulações comerciais".

É indiscutível que a inovação tecnológica é necessária, seja do ponto de vista da sociedade como um todo, que precisa dela para melhorar a sua qualidade de vida e do meio ambiente, ou do ponto de vista das empresas/indústrias, que precisam sobreviver no mercado, tendo também lucro. A questão é: será que a inovação tecnológica precisa ser um mal, para ser lucrativa? Será que uma formação diferenciada dos geradores de tecnologia (engenheiros, tecnólogos), que promova uma mudança de visão desses profissionais, não seria o caminho para abrandar esse mal? Afinal, sempre vai haver algum tipo de impacto promovido pelas inovações tecnológicas, sejam elas quais forem. Contudo, é possível suavizar a sua interferência tomando alguns cuidados, observando a diversidade dos aspectos envolvidos, ampliando o campo de visão de todos os seres humanos, ou ainda, assumindo que o desenvolvimento de inovações tecnológicas deve ocorrer de maneira consciente e responsável.

Para alguns (13\%) dos participantes da pesquisa, ciência, tecnologia e sociedade estão interligadas. Sobre isso vejamos, por exemplo, o que diz Thomas: 
"Na verdade a ciência e a tecnologia são da sociedade, é a própria questão da sociedade, não dá para desvincular, elas são parte inerente da sociedade. Agora como a ciência e a tecnologia vão contribuir para a sociedade isso é um caminho complexo. Você não tem como controlar isso. Então, eu acho que a ciência e a tecnologia dentro do papel da incubadora, ou melhor, a incubadora tem um papel institucional de você melhorar essas relações, agora se a ciência e a tecnologia têm um papel funcional eu diria que não, porque ela éparte inerente da sociedade, ela é parte integrante da sociedade, é inerente."

Esse tipo de postura nos dá a entender que a tecnologia é um mal necessário, no entanto, Miranda (2002) argumenta que a tecnologia é fruto da aliança entre ciência e técnica, produzindo a "razão instrumental", que, de acordo com a teoria crítica da Escola de Frankfurt, favoreceu o "agir-racional-com-respeito-a-fins". Habermas esclarece que tudo isso ocorre a serviço do poder político e econômico da sociedade baseada no modelo de produção capitalista (século XVIII), cujo lucro é a mola propulsora, advindo da produção e da expropriação da natureza.

Se considerarmos que a tecnologia moderna está inserida e se produziu num contexto social, político e econômico determinado, originando uma sociedade capitalista, então a nossa visão de tecnologia e o seu papel na sociedade deverá ser diferente daquela que prega que a tecnologia é um mal necessário, pois se compreendemos que ela surgiu em certo período histórico, ela não é tão antiga quanto a técnica, isto é, não é inerente à condição humana. Podese dizer, então, que é um fenômeno social, complexo, que nos guia a um posicionamento valorativo frente a ela. Por isso, existe a necessidade de repensar a direção dada à tecnologia, visando minimizar os riscos, sem, contudo, abdicar dos seus benefícios para a humanidade.

Rosana alerta para a necessidade de os empresários começarem a desenvolver inovações tecnológicas levando em consideração as questões sociais. Ela diz o seguinte:

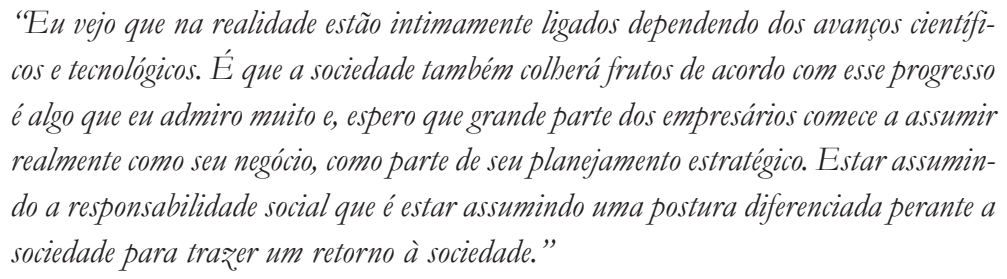

Essa narrativa reforça que o desenvolvimento científico e tecnológico com responsabilidade social deve-se voltar para tarefas práticas, não devendo ser dirigidos de acordo com os velhos sistemas econômicos, políticos e morais. Implica ter um nível de responsabilidade individual e coletiva muito mais acentuado do que anteriormente.

O depoimento de Jéferson amplia essa questão quando diz que é necessário investir em questões básicas como alimentação, saúde e educação.

"Nós temos 180 milhões de habitantes, tem quatro milhões ativos pelo menos na área que nós atuamos. Quatro milhões de pessoas é muito pouco ainda! Infelizmente, alguns países que deram certo, pelo menos é o que a gente lê, ou que estão dando certo dependeram de algumas atitudes que tomaram há 20, 30 anos atrás. Como a Índia que 
Silveira, R. M. C. F.; Bazzo, W.

começou investir mais na educação, mas eu não estou vendo isso no Brasil. Infelizmente, se eu não estou vendo esse investimento agora, então, daqui a 20, 30 anos não vou ver os frutos dessa forma de investimento."

Também, para Gustavo, a educação é que dá a base para “desenvolver pessoas mais conscientes e aptas a buscar soluções para as necessidades da comunidade onde elas vivem. Nesse ponto, a educação impulsiona encontrar soluções para resolver problemas do dia a dia".

Rosana acrescenta a importância das instituições tecnológicas proporcionarem uma formação que mostre a importância das relações sociais da ciência e da tecnologia:

"A universidade de tecnologia que trabalha com pesquisa e inovação, as quais devem estar direcionadas para a sociedade, tem que cuidar para ver se essa inovação vai trazer benefício ou mal para a sociedade. Eu já escrevi uma vez. um artigo que falava da tecnologia da informação instigando se ela é um bem ou um mal para a humanidade. Ao mesmo tempo em que traz beneficio, pode também estar prejudicando no sentido que nem todos têm acesso à informação. Infelizmente, nem toda a sociedade tem acesso a essa inovação e leva um tempo para se adaptar a toda essa tecnologia. Ex. Os caixas eletrônicos, como a população demorou a se adaptar e até hoje muitos não conseguem utilizar de serviços de autoatendimento."

Os relatos anteriores endossam as reflexões nas quais se propõe encorajar o desenvolvimento de inovações tecnológicas numa visão social, atentos às suas implicações para a sociedade no sentido de percebermos se toda e qualquer tecnologia nos interessa e de começarmos a fazer opções que visem diminuir os impactos causados pela sua utilização desenfreada. Concordamos com a opinião dos participantes da pesquisa sobre a necessidade de se buscar uma visão mais ampla, de repensar os rumos e valores, sem os quais os avanços tecnológicos e econômicos pouco representam; há uma distância enorme entre evolução das tecnologias e a evolução em outras instâncias de reprodução social.

Por isso, é preciso um controle no manejo de tecnologias fazendo um balanço da relação benefício-malefício do desenvolvimento científico e tecnológico para a sociedade e, nesse sentido, é preciso proporcionar, a toda a população, uma educação científica e tecnológica crítica, pois a ausência de conhecimento leva à falta de responsabilidade. Para Bernal (1969) o desenvolvimento científico e tecnológico deve ir ao encontro, primeiro, do que efetivamente as pessoas necessitam e, segundo, promover o desenvolvimento de pesquisas a fim de descobrir, combater ou destruir os males ainda não conhecidos.

Numa outra perspectiva, Elvira comenta que é necessária uma educação mais consistente, mas num contexto técnico, pois, segundo ela, a geração de tecnologia impõe que os profissionais tenham conhecimento mais consistente sobre o assunto. Para ilustrar essa questão, vejamos sua narrativa:

"Nós vemos que em relação à tecnologia, as pessoas que têm mais contato com a tecnologia começam a se preocupar, tem conhecimento melhor e pretendem investir nessa área, quando você começa estudar um pouco de tecnologia você já quer aplicá-la, quer ensinar para alguém e vai melhorando a cultura brasileira. Nós vemos que a maioria 
Ciência, tecnologia e suas relações sociais ...

das pessoas não têm muita educação, principalmente a educação de base é muito fraca.

Então, acaba não incentivando a geração de tecnologia, tem pessoas que nem sabem como chegar perto."

Ter uma formação acadêmica em um nível mais elevado para gerar tecnologia é considerado por Elvira como indispensável. Certamente, essa qualificação possibilita o desenvolvimento de pesquisa em tecnologia de ponta, mas será que é só de uma educação voltada para a tecnologia que a humanidade precisa? E as questões sociais não têm importância? Muitos problemas que vêm ocorrendo com a sociedade, como a degradação ambiental e o desemprego são decorrentes desse tipo de postura. Nesse sentido, Souza et al. (2003, p. 14) afirmam que a tecnologia de ponta, muitas vezes, "acaba reproduzindo a atual estrutura do mercado de trabalho, que cada vez mais tende a excluir profissionais de baixa qualificação e a aumentar as exigências da empregabilidade".

Autores como Buarque (1994), Garcia, Cerezo e López (1996), Bazzo (1998), Cerezo (2002), Bazzo, Von Linsingen e Pereira (2003), Arocena (2004), entre outros, também alertam para o perigo de se considerar a ciência e a tecnologia como uma panacéia, que só traz benefícios, e que fomentar o seu desenvolvimento poderia levar à superação do atraso tecnológico em relação aos países desenvolvidos. Segundo eles, esse radicalismo é inviável e tão perigoso quanto considerar o desenvolvimento de inovações tecnológicas como prejudicial, servindo só para promover o subdesenvolvimento.

Por isso, a necessidade de se ter prudência tanto na geração de tecnologia quanto na sua utilização, ou seja, é necessário haver uma mudança de atitude e de comportamento que procure o outro mundo que desejamos; mas para que isso ocorra, é indispensável fornecer educação de maneira contínua para todos os seres humanos, de forma a viabilizar a participação dos debates sobre questões científicas e tecnológicas. Arocena (2004) expõe os dados da Organization for Economic Co-Operation and Development (OECD), os quais mostram que, nos países que compõem essa organização, de cada dez cidadãos, no máximo dois estariam em condições de seguir e participar de uma discussão que inclua questões científicas ou tecnológicas, ou mesmo relacionadas a outros temas como, por exemplo, o financeiro.

\section{Considerações finais}

Os relatos dos entrevistados evidenciam que a grande maioria dos participantes da pesquisa possui uma visão ainda incipiente do desenvolvimento científico e tecnológico. Eles estão mais ligados aos conhecimentos técnicos e econômicos, sem considerar as relações sociais do desenvolvimento de inovações tecnológicas, o que parece ser fruto da sua formação profissional, que faz com que fiquem submersos cada qual em seu tecnicismo especial, sem a educação panorâmica que só a universidade pode proporcionar, mas que não é feito. Dessa forma, são incapazes de afrontar ou prever o problema que a tecnologia delineia hoje para a humanidade.

Esperamos que esses valores culturais mudem nas próximas gerações. Para isso, é necessário investir-se na formação da população, de maneira que se possa oferecer uma educação científica e tecnológica que se preocupe, também, com as implicações sociais dos desenvolvimentos de inovações tecnológicas. 
Silveira, R. M. C. F.; Bazzo, W.

Para formar profissionais da área tecnológica que compreendam o mundo em que vivem, tanto do ponto de vista dos fenômenos naturais, quanto sociais, de modo que eles possam participar de forma crítica e consciente dos debates e decisões que permeiam a sociedade, é necessário repensar a educação tecnológica. Desse modo, colocamos a educação CTS como uma proposta para a formação dos educadores e educandos, em que ocorra uma nova postura, além do academicismo e cientificismo. A preocupação com as questões sociais da mudança científico-tecnológica favorece a edificação de atitudes, valores e normas, de maneira que os estudantes possam participar ativa e responsavelmente do debate político e público sobre questões relacionadas com o desenvolvimento de inovações científico-tecnológicas.

A ideia de se fornecer, para os alunos da educação tecnológica, o debate sobre as relações existentes entre ciência, tecnologia e sociedade vem sendo difundida também nas Diretrizes Curriculares Nacionais (DCNs) dos cursos de engenharia e superiores de tecnologia, que têm proposto uma formação mais humanista, crítica e reflexiva acerca dos aspectos sociais, econômicos e culturais resultantes da produção, gestão e incorporação de novas tecnologias. Para isso, a organização curricular desses cursos deverá contemplar, além dos fundamentos científicos e tecnológicos, também os humanísticos, necessários ao desempenho do graduado na área tecnológica. Dessa forma, tal educação tecnológica estaria comprometida com a perspectiva de superar a visão ingênua da tecnificação da ciência e da tecnologia como forma de progresso humano.

No entanto, apenas constar nas DCNs não basta. É preciso aprofundar a discussão de tais diretrizes entre os professores da educação tecnológica, para encontrar alternativas adequadas a serem seguidas em um trabalho coletivo, visando formar profissionais da área tecnológica de modo a relacionar os fenômenos naturais e sociais, para uma participação crítica e consciente dos debates e decisões que permeiam a sociedade. 
Ciência, tecnologia e suas relações sociais ...

\section{Referências}

ANDRÉ, M. E. D. A. Etnografia da prática escolar. Campinas: Papirus, 1995.

AROCENA, R. Riesgo, cambio técnico y democracia en el subdesarrollo. In: LUJÁN, J. L.; ECHEVERRÍA, J. (Orgs.). Gobernar los riesgos: ciencia y valores en la sociedad del riesgo. Madrid: Biblioteca Nueva/Organização dos Estados Ibero-americanos, 2004. p. 207-223.

BASTOS, J. A .S. L. A. Educação e tecnologia (DIGIT). Apostila apresentada na disciplina de Filosofia e História da Educação Tecnológica no Mestrado em Tecnologia do PPGTE do CEFET-PR, 1998.

BAZZO, W. A. Ciência, tecnologia e sociedade: o contexto da educação tecnológica. Florianópolis: Ed. da UFSC, 1998.

.; VON LINSINGEN, I.; PEREIRA, L. T. V. Introdução aos estudos CTS

(Ciência, Tecnologia e Sociedade). Madri: Organização dos Estados Ibero-americanos, 2003.

BERNAL, J. D. Ciência na história. Lisboa: Livros Horizonte, 1969. v. VII.

BUARQUE, C. R. C. A revolução nas prioridades: da modernidade técnica à modernidade ética. São Paulo: Paz e Terra, 1994.

CARSON, R. Silent spring. Houghton Miffin: Nueva York, 1962.

CEREZO J. A. Ciência, tecnologia e sociedade: o estado da arte na Europa e nos Estados Unidos. In: SANTOS, L. W. et al. (Orgs.). Ciencia, tecnologia e sociedade: o desafio da interação. Londrina: IAPAR, 2002. p. 3-39.

ECHEVERRÍA, J. Filosofía de la ciencia. Madrid: Akal, 1995.

GARCIA, M. I. G.; CEREZO, J. A. L.; LÓPEZ, J. L. Ciencia, tecnología y sociedad: una introducción al estudio social de la ciencia y la tecnología. Madrid: Editorial Tecnos, 1996.

HOBSBAWN, E. A era dos extremos: o breve século XX. São Paulo: Cia. das Letras, 1995.

JONASH, R. S.; SOMMERLATT, T. O valor da inovação: como as empresas mais avançadas atingem alto desempenho e lucratividade. Rio de Janeiro: Campus, 2001.

KUHN, T. S. The structure of scientific revolutions. 2. ed. Chicago: University of Chicago Press, 1962.

LÓPEZ, J. L. L.; CEREZO, J. A. L. Educación CTS en acción: enseñanza secundaría y universidad. In: GARCIA, M. I. G.; CEREZO, J. A. L.; LOPEZ, J. L. (Orgs.). Ciencia, tecnología y sociedad: una introducción al estudio social de la ciencia y la tecnología. Madrid: Editorial Tecnos, 1996. p. 225-252.

;___ De la promoción a la regulación. El conocimiento científico en las políticas públicas de Ciencia e Tecnología. In: LUJÁN, J. L.; ECHEVERRÍA, J. (Orgs.). Gobernar los riesgos: ciencia y valores en la sociedad del riesgo. Madrid: Biblioteca Nueva/Organização dos Estados Ibero-americanos, 2004. p. 254-272. 
Silveira, R. M. C. F.; Bazzo, W.

MARCOVITCH, J. Universidad e innovación tecnológica. In: ORGANIZACIÓN DOS ESTADOS IBEROAMERICANOS PARA LA EDUCACIÓN, LA CIÊNCIA Y LA CULTURA (OEI). Innovación tecnológica, universidad y empresa. Madrid: Organização dos Estados Ibero-americanos, 2003. p. 355-364.

MIRANDA, A. L. Da natureza da tecnologia: uma análise filosófica sobre as dimensões ontológica, epistemológica e axiológica da tecnologia moderna. 2002. 161f. Dissertação (Mestrado em Tecnologia) - Programa de Pós-graduação em Tecnologia, Centro Federal de Educação Tecnológica do Paraná, Curitiba, 2002.

PINTO, Á. V. O conceito de tecnologia. Rio de Janeiro: Contraponto, 2005. v. 2.

SANMARTÍN, J. et al. Estudios sobre sociedad y tecnología. Barcelona: Anthropos, 1992.

SANTOS, B. Crítica da razão indolente contra o desperdício da experiência. São Paulo: Cortez, 2000.

SOUZA, M. C. A. F. et al. Incubadora Tecnológica de Cooperativas - ITCP x Incubadora de Empresa de Base Tecnológica - IEBT - diferenças e semelhanças no processo de Incubação. Revista Iberoamericana de Ciência, Tecnologia e Sociedad e Innovación, Madri, n. 6, 2003. Disponível em: <http://www.oei.es/revistactsi/numero6/ articulo01.htm>. Acesso em: 12 jun. 2006.

Artigo recebido em março de 2009 e aceito em outubro de 2009. 